\title{
Historical Perspective of Dharwad Forensic Mental Health Services during Pre-Independence Era: A Retrospective Study
}

\author{
Raveesh $\mathrm{BN}^{1}$, Ranganath $\mathrm{RK}^{* 2}$ and Ragavendra $\mathrm{BN}^{2}$
}

${ }^{1}$ Director, Dharwad Institute of Mental Health \& Neurosciences (DIMHANS), Dharwad, India

${ }^{2}$ Associate Professor of Psychiatry, Dharwad Institute of Mental Health \& Neurosciences, Dharwad, India

*Corresponding author: Ranganath RK, Associate Professor of Psychiatry, Dharwad Institute of Mental Health \& Neurosciences, Dharwad, India, E-mail: dranant007@rediffmail.com

Citation: Raveesh BN, Ranganath RK, Ragavendra BN (2017) Historical Perspective of Dharwad Forensic Mental Health Services during Pre-Independence Era: A Retrospective Study. J Forensic Sci Criminol 5(3): 301

Received Date: March 14, 2017 Accepted Date: May 30, 2017 Published Date: April 01, 2017

\begin{abstract}
Background: History of forensic mental health services provide knowledge regarding its evolution that has undergone tremendous changes over the past two centuries.

Aim: To study the forensic mental health services and management of psychiatric patients during pre-independence era.

Settings and Design: Retrospective, hospital based chart-review and descriptive study.

Methods and Materials: Medical records of 85 cases preserved with the 170-year old psychiatric institute were retrieved to study the variables related to socio-demographic characteristics, family background, clinical profile, treatment methods, admission-discharge procedures, and mortality by retrospective chart-review method. Data was analysed using descriptive statistical measures with significance of $\mathrm{P}<0.05$.

Results: Mean age of the sample was $32.53 \pm 9.65$ years with male preponderance (3:1). Mean duration of illness was $16.19 \pm 37.88$ months with mean duration of hospitalization of $23.01 \pm 46.24$ months. $98 \%$ cases had at least one psychiatric disorder, with most common being mood disorders (54\%), psychotic disorders (30.6\%), and substance-related disorders (23.5\%). Psychiatric comorbidity (15.6\%) with male preponderance, and comorbid physical illnesses $(36.5 \%)$ with significant female preponderance $\left(\mathrm{x}^{2}=4.19 ; \mathrm{P}<0.05\right)$ was noted. Mortality rate of $30 \%$ due to serious physical illnesses was noted. Medical management included sedative/anti-epileptic agents and/or camphorinduced seizures, with seclusions used only in $13 \%$ cases.

Conclusion: Dharwad mental health services provide historical information about patient care and legislative measures of preindependence era. Longer remission and hospitalization duration, higher mortality reflect lack of effective pharmacological measures and scientific treatment methods that got established after 1950s.
\end{abstract}

Keywords: British Lunacy Asylum Act 1856; Indian Lunacy Act 1912; Mental Health Act 1987; Psychiatric illness; Admission; Discharge; Mental health services; History; Psychiatry

\section{Introduction}

In $21^{\text {st }}$ century, writing the recent history of mental health services requires a conscious departure from the historiographical tropes of the past three centuries which have emphasised the experience of those identified (and legally defined) as 'lunatics' and the social, cultural, political, medical and institutional context of their treatment. A historical narrative structured around rights (to health and liberty) is now complicated by the rise of new organising categories such as 'costs', 'risks', 'needs' and 'values'[1]. In this article, we summarise the historical perspective of mental health services as well as the growth and development of an institution over the past two centuries. The current study compiles the historical data from available century-old mental health records that reflect the challenging medico-legal scenarios witnessed by the persons with mental illness (PwMI) and mental health professionals during pre-independence era in India.

\section{History of mental health services}

In India, till about $17^{\text {th }}$ century all abnormal behaviours were believed to be act of the 'devil' and 'mentally ill' were considered evil and described as witches [2]. Gradually over the $17^{\text {th }}-18^{\text {th }}$ century, mental illness was considered as 'deviant behaviour' and mentally ill as socially unacceptable, only to be detained in jails along with other criminals. 'Mentally ill' were coined as 'mad', 'lunatic' or 'insane' confined in isolated and protected special places called as 'lunatic asylums' providing minimum basic needs, 
with paramount importance given to protection of the society from such persons [3].

Institutional arrangements for PwMI during pre-British period in India was scarce, except very few during reigns of King Ashoka (268-232 BCE), Cholas period (Tamil Nadu), and Mandu Hospital, at Dhār (Madhya Pradesh; 1436-1469), the latter being the first mental asylum. Developments of lunatic asylums at Calcutta, Madras and Bombay were almost parallel to the political events taking place in each region. The conflicts between French and English, Marathas and Sikhs for supremacy gave rise to political instability and also contributed to psychological and social turmoil. As need to establish and regulate hospitals became more acute, mainly to treat Englishmen and Indian sepoys employed by British East India Company, many legislative measures were enacted for caring PwMI such as - Act of regulating mad houses (1794); County Asylum Act (1808); Lunatic Act (1845), Pauper Lunatics Act (1845), Lunacy Regulation Act (1853), Lunacy Care and Treatment Amendment Act (1853), and Lunatic Asylums Amendment Act (1853).

The suppression of freedom movement in 1857 and transfer of the powers of East India Company by British Crown on $1^{\text {st }}$ November, 1858 resulted in changes in the legislation for caring PwMI such as Indian Lunatic Asylums Act (Act 36 of 1858) that laid down guidelines for the establishments of mental asylums and set the procedure for their admission. There were discernable growth in number of lunatic asylums and local population was also permitted to avail these facilities. During late $17^{\text {th }}$ century, many lunatic asylums were started such as Bombay asylum (1750), Kilpauk asylum in Madras (1794), Monghyr asylum for insane soldiers in Bihar (1795), Thana asylum, Dharwar asylum (1845), and Yerwada asylum in Poona (1889) [2]. Later, as the need for central supervision of all the lunatic asylums was felt, Indian Lunacy Act 1912 (Act 4 of 1912) was enacted.

\section{Lunatic Asylum, Dharwar (1845-1922)}

The Bombay Provincial mental health services embraced a number of institutions utilising buildings of various styles of architecture. The current edifice, Dharwad institute of mental health and neurosciences (DIMHANS) started as a "Lunatic Ayslum" in the year 1845 by the British Raj as per the letter dated 25-9-1908 of Superintendent Engineer of southern division of Bombay Presidency. The asylum at Dharwad is one of the five 'lunatic' asylums in southern part of the Bombay Presidency, others being at Yerwada (Poona), Colaba, Ratnagiri and Thana, thus making it second oldest 'lunatic' asylum in the Deccan India. The elaborately landscaped vegetated grounds at Dharwar lunatic asylum, then about 2-3 miles from District Headquarters and now within city, are the site of ten huge high-ceiling, single-storied buildings built with lime, mortar and bricks, red-tiled thatched roof, supported by teakwood logs, have stood strong till today for more than 170 years, that housed more than 1200 patients every year [4].

In 1885, following overcrowding of the Dharwar lunatic asylum, there was an increase in the financial and social burden on the British government to maintain the asylum, and some rooms in the nearby jail were converted into wards. In 1889 , the Government thought of closing down the asylum, but it was turned down by Surgeon-General with the Government of Bombay. For unknown reasons, it was later planned to shift the asylum to Belgaum and temporary occupation of deserted building was sought which faced protest at both cantonment and military force of Belgaum. Later the Government ordered the Commissioner and Surgeon-General to construct main buildings for the asylum in Belgaum and opined - "They should, if possible be on the eminence in order to ensure free ventilation for the asylum and cheerful scenery", but it did not materialize. The Surgeon-General with the Government of Bombay took the matter seriously and wrote to the Government on 8-7-1893 “...the abolition of Dharwad asylum would lead to overcrowding in other asylums, and perhaps to the necessity for additions to them; and as the difficulty and expenses of sending the insane of the southern Maratha country to distant asylum would be considerable, I am of the opinion that the permanent management of Dharwad asylum should be sanctioned." The asylum was a part of Jail until 1909 when a compound wall was built around the asylum separating it from the jail [4].

In 1921, Bombay Province Government in its order clarified - “....those with annual income less than one thousand rupees to be considered as 'pauper' and given free treatment in mental asylum, and others to be charged with six annas a day on account of care and maintenance charges during hospitalisation.... if mentally ill is a habitual resident as per municipal records within any municipal limits or a frequent visitor to municipal limits then such municipality to pay the maintenance charges of the mental patients". Such charges collected were deposited into the Government treasury with Imperial Bank of India, money transferred between public departments or by postal transfers.

Discharge of patients was assessed by the asylum committee members constituted by Collector and District Magistrate, Superintendent of Lunatic Asylum, Civil Surgeon of Dharwar, Assistant Collector of Dharwar, and Retired District Deputy Collector of Dharwar. Half-yearly visits by the committee for criminal 'lunatics' was also undertaken to evaluate their health and fitness to stand a trial. Medical and mental fitness for discharge of sepoys with mental illnesses were evaluated by the medical board at Indian Station Hospital (now Military Hospital) at Belgaum for their fitness to join duty. British superintendents who served Lunatic asylum, Dharwar were Lt. Col. CT Hudson (1896-1915), Lt. Col. GE Fooks (1915-20), and Lt. Col. AFW King (1920-24).

\section{Mental Hospital, Dharwar (1922-1992)}

Later in the year 1922, British Government declared it as "Government Mental Hospital” following availability of some traditional treatment methods [4]. The care of PwMI continued as per the directions of Indian Lunacy Act, 1912. British superintendents like Lt. Col. AFW King (1920-24), Lt. Col. JL Lunham (1924-29), Major Basil Franklin Eminsen (1929-32), Major BZ Shah (1932-35) 
and Lt. Col. FR Thornton (1935-41) served mental hospital. The hospital has served since its inception the guiding legislature for admission and discharge of persons with mental illness such as Indian Lunacy Asylums Act, Act 36 of 1858 and Indian Lunacy Act, Act 4 of 1912 and currently serving as per the Mental Health Act, 1987.

After India's independence in 1947, the hospital was under the additional in-charge of District Surgeon of Dharwad. In the year 1960, separate hospital staffs were recruited and Prof. S M Channabasavanna was the first psychiatrist and medical superintendent who initiated scientific methods of using psychotropic medications and electroconvulsive therapy (ECT). During this period outpatient services at Karnataka Medical College and Hospital, Hubli were initiated and medical under-graduates were posted for training in psychiatry. In the year 1980, Karnataka University of Dharwad recognised the mental hospital as a teaching hospital, and post-graduate diploma courses in psychological medicine were started for the first time. It was the premier institute of mental health for the Bombay Karnataka region and surrounding districts during this period. Later, due to lack of skilled manpower and teaching faculty, academic services were discontinued in 1989 [4].

\section{Karnataka Institute of Mental Health (1992-2009)}

In the year 1992, State Government converted this institute into teaching institute under the Department of Medical Education and renamed it as Karnataka Institute of Mental Health. Adequate infrastructure facilities such as new building for out-patient services with 13 rooms, pharmacy, emergency ward, in-patient services (eight wards with each of 20 beds capacity), special wards, ECT room with anaesthesia facilities, laboratory and radiology services were made available. Allied mental health professionals were recruited. However, lack of teaching faculty and mental health professionals during this period delayed its vision of developing into a medical institution [4].

\section{Dharwad Institute of Mental Health and Neurosciences (2009 to 2016)}

With a vision to establish into a "Centre of Excellence" for developing manpower in mental health on the lines of National Institute of Mental Health and Neurosciences, Bengaluru (established 1954), based on the recommendations of Hon'ble Justice Dr. Nanjundappa's report on correction of regional disparities in Karnataka, the institute was converted into an autonomous postgraduate training institute in the year 2009 and renamed as Dharwad Institute of Mental Health and Neurosciences (DIMHANS). Teaching faculty in the fields of psychiatry and allied mental health (clinical psychology, psychiatric social work, psychiatric nursing), neurology, neurosurgery and anaesthesia were recruited during the years 2011-14. Post-graduation courses in psychiatric nursing since 2013 and psychiatry (2014) have been initiated [5].

The 170-year-old institute now has a multidisciplinary approach with teaching faculties in psychiatry, clinical psychology, psychiatric social work, psychiatric nursing, neurology, neurosurgery and anaesthesia. The institute caters to the needs of nearly 400-450 patients per day who visit from majority districts of North Karnataka, Telangana, Andhra Pradesh, Goa and Maharashtra. The institute offers psychiatry services on outpatient and in-patient basis; has separate de-addiction ward, forensic ward, child and adolescent psychiatry ward, and psychiatric rehabilitation centre. Family counselling services are offered both at out-patient and in-patient basis. Community mental health programmes, school mental health programmes, prison mental health visits, and police mental health education programmes are initiated to cater mental health awareness to the society. Department of clinical psychology offers psychological evaluations and interventions. Department of psychiatric social work offers social services and disability evaluation for PwMI. Institute also offers free legal aid clinic for the needy PwMI about provisions under Mental Health Act, 1987 and human rights of PwMI [5].

The development of this institution from meagre beginnings in 1845 was thought to be worthy of a review. As a consequence, this article was prepared after studying the original case records, drug-indent book, and stamps registry of those times, with the intention to study the historical perspective of mental health services of second oldest lunatic asylum of south India. Ancient medical records of patients have been diligently maintained since more than a century which serves as a vital resource for current research into the past to know about the manner in which the patients were admitted, managed and discharged from the hospital during the pre-ECT era. Hence the current study of the psychosocial and medicolegal profile of PwMI to understand the clinical scenario during pre-independence era was undertaken.

\section{Materials and Methods}

The current study is a retrospective, hospital-based, chart-review, and descriptive study. Ethical clearance was obtained from the Institutional Ethics Committee. Data from the ancient medical records of 85 cases (1886-1941) preserved at the medical records department of DIMHANS was retrieved. Variables related to socio-demographic characteristics, mode of admission-discharge procedures, clinical characteristics, manner of management, morbidity, physical health and mortality causes were reviewed. Data was tabulated and results were analysed using descriptive statistical measures with $\mathrm{P}$ value $<0.05$.

\section{Results}

\section{Socio-demographic characteristics}

The age range of the study sample admitted to mental health centre was 16-70 years, with more than three-fourths ( $\mathrm{n}=47$ ) aged between 21 to 40 years. The mean age of the sample was $32.53 \pm 9.65$ years. There were 63 males and 22 females. Majority of 
the subjects were from rural background (58.82\%; $\mathrm{n}=50)$ and were Hindus $(74.12 \% ; \mathrm{n}=63)$. Although, illiterates $(76.47 \% ; \mathrm{n}=65)$ outnumbered literates; nearly two-thirds of the cases $(62.35 \% ; n=53)$ lived doing semi-skilled and skilled work. Majority of sample $(84.71 \% ; \mathrm{n}=72)$ were from lower socioeconomic status and declared as 'pauper' with annual income less than one thousand rupees by the court and municipal authorities. Seventy percent $(n=60)$ were unmarried, separated or widow/er, and $40 \%(n=34)$ stayed in joint family and $32 \%(n=27)$ were destitutes (Table-1).

\begin{tabular}{|c|c|c|c|}
\hline Characteristics & Total=85 (\%) & Male $=63(\%)$ & Female $=22(\%)$ \\
\hline \multicolumn{4}{|l|}{ Age in years (range:16-70) } \\
\hline Mean and S.D & $32.53 \pm 9.65$ & $33.62 \pm 9.3$ & $32.27 \pm 10.82$ \\
\hline$\leq 20$ & $5(5.88)$ & $3(4.76)$ & $2(9.09)$ \\
\hline $21-30$ & $42(49.41)$ & $31(49.21)$ & $11(50.0)$ \\
\hline $31-40$ & $24(28.24)$ & $19(30.16)$ & $5(22.73)$ \\
\hline $41-50$ & $12(14.12)$ & $9(14.29)$ & $3(13.64)$ \\
\hline$\geq 51$ & $2(2.35)$ & $1(1.59)$ & $1(4.55)$ \\
\hline Sex & $85(100)$ & $63(74.12)$ & $22(25.88)$ \\
\hline \multicolumn{4}{|l|}{ Place of residence } \\
\hline Rural & $50(58.82)$ & $38(60.32)$ & $12(54.55)$ \\
\hline Urban & $35(41.18)$ & $25(39.68)$ & $10(45.46)$ \\
\hline \multicolumn{4}{|l|}{ Religion } \\
\hline Hindu & $63(74.12)$ & $43(68.25)$ & $20(90.91)$ \\
\hline Muslim & $18(21.18)$ & $18(28.57)$ & $0(0)$ \\
\hline Christian & $4(4.71)$ & $2(3.17)$ & $2(9.09)$ \\
\hline \multicolumn{4}{|l|}{ Education } \\
\hline Illiterate & $65(76.47)$ & $45(71.43)$ & $20(90.91)$ \\
\hline Literate & $20(23.53)$ & $18(28.57)$ & $2(9.09)$ \\
\hline \multicolumn{4}{|l|}{ Occupation } \\
\hline Unemployed & $14(16.47)$ & $8(12.7)$ & $6(27.27)$ \\
\hline Semi-skilled & $24(28.23)$ & $21(33.33)$ & $3(13.64)$ \\
\hline Self/skilled & $29(34.12)$ & $27(42.86)$ & $2(9.09)$ \\
\hline Government/Military & $5(5.88)$ & $4(6.35)$ & $1(4.55)$ \\
\hline Household & $11(12.94)$ & $1(1.59)$ & $10(45.46)$ \\
\hline Student & $2(2.35)$ & $2(3.17)$ & $0(0)$ \\
\hline \multicolumn{4}{|l|}{ Socioeconomic status } \\
\hline Annual income Rs. $<1000$ (pauper) & $72(84.71)$ & $52(82.54)$ & $20(90.91)$ \\
\hline Annual income Rs. > 1000 & $13(15.29)$ & $11(17.46)$ & $2(9.09)$ \\
\hline \multicolumn{4}{|l|}{ Marital status } \\
\hline Single & $49(57.65)$ & $38(60.32)$ & $11(50)$ \\
\hline Married & $25(29.41)$ & $21(33.33)$ & $4(18.18)$ \\
\hline Separated/Widow/er & $11(12.94)$ & $4(6.35)$ & $7(31.82)$ \\
\hline \multicolumn{4}{|l|}{ Family type } \\
\hline Nuclear & $9(10.59)$ & $8(12.7)$ & $1(4.55)$ \\
\hline Extended & $15(17.65)$ & $14(22.22)$ & $1(4.55)$ \\
\hline Joint & $34(40.00)$ & $29(46.03)$ & $5(22.73)$ \\
\hline Destitute/unknown & $27(31.77)$ & $12(19.05)$ & $15(68.18)$ \\
\hline
\end{tabular}

Table 1: Socio-demographic characteristics of patients admitted to mental health centre, Dharwad.

\section{Clinical variables}

Three-fourth of the sample ( $n=64)$ was admitted for first episode psychiatric illness. Mean duration of psychiatric illness prior to admission was $16.19 \pm 37.88$ months, with $77 \%(n=66)$ suffering from illness up to six months. Nearly $40 \%(n=32)$ were wandering or naked, and one-third cases $(n=29)$ had suicidal or homicidal tendencies prior to admission. Twenty-eight percent of cases $(\mathrm{n}=24)$ had family history of psychiatric disorders or suicide (Table-2).

Psychiatric morbidity and comorbidity: $98 \%(n=83)$ of the cases had at least one psychiatric disorder, with $15.66 \%(n=13)$ cases having psychiatric comorbidity. Very few $(2.32 \%)$ cases had no diagnosable psychiatric disorders while under observation. Mood 
disorders (54\%; $\mathrm{n}=46)$, psychotic disorders $(30.6 \% ; \mathrm{n}=26)$, and substance related disorders $(23.5 \%$; $=20)$ were the most common psychiatric conditions. Among mood disorders, bipolar disorder was predominant $(85 \% ; n=39)$ with melancholia seen in $15 \%$ $(\mathrm{n}=8)$ cases. Among psychotic disorders, schizophrenia was predominant $(54 \% ; \mathrm{n}=14)$. Among substance use disorders, cannabis abuse/dependence $(44.4 \% ; n=8)$ and poly-substance abuse/dependence $(27.8 \% ; n=5)$ was commonly noted. Male preponderance was noted with melancholia $(n=8)$ and substance use disorders $(n=16)$, especially poly-substance abuse/dependence (cannabis, alcohol, tobacco, sniffing). Female preponderance $(40.91 \% ; n=9)$ was noted with schizophrenia.

\begin{tabular}{|c|c|c|c|}
\hline Characteristics & Total $=85(\%)$ & Male $=63(\%)$ & Female $=22(\%)$ \\
\hline \multicolumn{4}{|l|}{ Duration of illness } \\
\hline Mean and S.D. & $16.19 \pm 37.88$ & $15.81 \pm 39.00$ & $17.28 \pm 35.30$ \\
\hline$<1$ month & $27(31.77)$ & $21(33.33)$ & $6(27.27)$ \\
\hline 1-6 months & $39(45.88)$ & $27(42.86)$ & $11(50)$ \\
\hline$>6-24$ months & $7(8.24)$ & $5(7.94)$ & $1(4.55)$ \\
\hline$>24$ months & $14(16.47)$ & $10(15.87)$ & $4(18.18)$ \\
\hline \multicolumn{4}{|l|}{ No. of episodes ${ }^{*}$} \\
\hline Mean and S.D. & $1.4 \pm 0.9$ & $1.4 \pm 0.83$ & $1.41 \pm 1.09$ \\
\hline First episode & $64(75.29)$ & $47(74.60)$ & $17(77.27)$ \\
\hline Recurrent & $21(24.71)$ & $16(25.39)$ & $5(22.72)$ \\
\hline Wandering/Naked $\dagger$ & $32(37.65)$ & $24(38.09)$ & $8(36.36)$ \\
\hline Suicidal/homicidal behaviour & $29(34.12)$ & $24(38.09)$ & $5(22.73)$ \\
\hline $\begin{array}{c}\text { Family history of psychiatric illness / } \\
\text { suicide§ }\end{array}$ & $24(28.24)$ & $16(25.4)$ & $8(36.36)$ \\
\hline Family communication|| & $28(32.94)$ & $23(36.51)$ & $5(22.73)$ \\
\hline Health status & $7(25.0)$ & $2(8.69)$ & $5(100)$ \\
\hline Discharge & $19(67.86)$ & $19(82.61)$ & $0(0)$ \\
\hline Maintenance charge & $2(7.14)$ & $2(8.69)$ & $0(0)$ \\
\hline \multicolumn{4}{|l|}{ Hospitalization (range: $0.033-360$ ) } \\
\hline Mean and S.D. & $23.01 \pm 46.24$ & $22.41 \pm 51.33$ & $24.71 \pm 27.75$ \\
\hline$\leq 1$ month & $10(11.76)$ & $6(9.52)$ & $4(18.18)$ \\
\hline$>1-6$ months & $31(36.47)$ & $21(33.33)$ & $10(45.45)$ \\
\hline$>6-24$ months & $27(31.76)$ & $19(30.16)$ & $8(36.36)$ \\
\hline$>24-60$ months & $6(7.06)$ & $6(9.52)$ & $0(0)$ \\
\hline$>60-120$ months & $10(11.76)$ & $10(15.87)$ & $0(0)$ \\
\hline$>120$ months & $1(1.18)$ & $1(1.59)$ & $0(0)$ \\
\hline Use of seclusions & $11(12.94)$ & $10(15.87)$ & $1(4.55)$ \\
\hline Psychiatric diagnosis & $83(97.65)$ & $61(96.83)$ & $22(100)$ \\
\hline Acute mania & $43(50.59)$ & $33(52.38)$ & $10(45.45)$ \\
\hline Insanity & $32(37.65)$ & $22(34.92)$ & $10(45.45)$ \\
\hline Substance abuse/dependence & $18(21.18)$ & $16(25.4)$ & $2(9.09)$ \\
\hline Polysubstance & $5(27.77)$ & $5(31.25)$ & $0(0)$ \\
\hline Cannabis & $8(44.44)$ & $7(43.75)$ & $1(50.0)$ \\
\hline Tobacco & $4(22.22)$ & $4(25.0)$ & $1(50.0)$ \\
\hline Alcohol & $3(16.66)$ & $2(12.5)$ & $1(50.0)$ \\
\hline Sniffing & $1(5.55)$ & $1(6.25)$ & $0(0)$ \\
\hline Melancholia & $8(9.41)$ & $8(12.69)$ & $0(0)$ \\
\hline Epilepsy & $9(10.59)$ & $7(11.11)$ & $2(9.09)$ \\
\hline \multicolumn{4}{|l|}{$\begin{array}{l}\text { Equivalent ICD-10 diagnosis6 } \\
\text { (tentative) }\end{array}$} \\
\hline F03 & $1(1.18)$ & $1(1.59)$ & $0(0)$ \\
\hline F05 & $1(1.18)$ & $1(1.59)$ & $0(0)$ \\
\hline F10 & $3(3.53)$ & $2(3.18)$ & $1(4.55)$ \\
\hline F12 & $8(9.41)$ & $7(11.11)$ & $1(4.55)$ \\
\hline
\end{tabular}




\begin{tabular}{|c|c|c|c|}
\hline F17 & $4(4.71)$ & $3(4.76)$ & $1(4.55)$ \\
\hline F19 & $5(5.88)$ & $5(7.94)$ & $0(0)$ \\
\hline F20 & $14(16.47)$ & $5(7.94)$ & $9(40.91)$ \\
\hline F23 & $5(5.88)$ & $5(7.94)$ & $0(0)$ \\
\hline F25 & $2(2.35)$ & $2(3.18)$ & $0(0)$ \\
\hline F29 & $5(5.88)$ & $4(6.35)$ & $1(4.55)$ \\
\hline F30 & $15(17.65)$ & $12(19.05)$ & $3(13.63)$ \\
\hline $\mathrm{F} 31$ & $24(28.24)$ & $18(28.57)$ & $6(27.27)$ \\
\hline F32 & $7(8.24)$ & $7(11.11)$ & $0(0)$ \\
\hline F70-79 & $2(2.35)$ & $0(0)$ & $2(9.09)$ \\
\hline G40 & $9(10.59)$ & $6(9.52)$ & $3(13.63)$ \\
\hline Physical illnesses comorbidity ${ }^{* *}$ & $31(36.47)$ & $19(30.16)$ & $12(54.54)$ \\
\hline Severe anaemia & $6(19.35)$ & $4(21.05)$ & $2(16.67)$ \\
\hline Organic & $2(6.45)$ & $2(10.52)$ & $0(0)$ \\
\hline Epilepsy & $9(29.03)$ & $6(31.58)$ & $3(25.0)$ \\
\hline Febrile illnesses & $17(54.84)$ & $9(47.37)$ & $8(66.67)$ \\
\hline Dysentery & $5(29.41)$ & $3(33.33)$ & $2(25.0)$ \\
\hline Tuberculosis & $3(17.65)$ & $0(0)$ & $3(37.5)$ \\
\hline Pneumonia & $2(11.76)$ & $2(22.22)$ & $0(0)$ \\
\hline Myocarditis & $1(5.88)$ & $0(0)$ & $1(12.5)$ \\
\hline Septic cellulitis & $1(5.88)$ & $1(11.11)$ & $0(0)$ \\
\hline Malaria & $1(5.88)$ & $0(0)$ & $1(12.5)$ \\
\hline Syphilis & $1(5.88)$ & $1(11.11)$ & $0(0)$ \\
\hline Unknown causes & $3(17.65)$ & $0(0)$ & $1(12.5)$ \\
\hline Full remission & $55(64.71)$ & $42(66.67)$ & $13(59.09)$ \\
\hline$\leq 1$ month & $24(43.64)$ & $20(47.62)$ & $4(30.77)$ \\
\hline$>1-6$ months & $20(36.36)$ & $14(33.33)$ & $6(46.15)$ \\
\hline$>6-24$ months & $11(20.0)$ & $8(19.05)$ & $3(23.08)$ \\
\hline Partial/ chronic/Non-remission & $23(27.06)$ & $14(22.22)$ & $9(40.91)$ \\
\hline Discharge $\dagger$ & $60(70.59)$ & $47(74.60)$ & $13(59.09)$ \\
\hline sent home & $39(65.0)$ & $31(65.95)$ & $8(61.54)$ \\
\hline Sent home with allowances & $21(35.0)$ & $16(34.04)$ & $5(38.46)$ \\
\hline Mortality & $25(29.41)$ & $16(25.4)$ & $9(40.91)$ \\
\hline Severe anaemia with CCF & $8(32.0)$ & $7(43.75)$ & $1(11.11)$ \\
\hline Epilepsy coma & $5(20.0)$ & $4(25.0)$ & $1(11.11)$ \\
\hline Heart failure & $3(12.0)$ & $2(12.5)$ & $1(11.11)$ \\
\hline Tuberculosis & $3(12.0)$ & $0(0)$ & $3(33.33)$ \\
\hline Dysentery & $2(8.0)$ & $1(6.25)$ & $1(11.11)$ \\
\hline $\begin{array}{l}\text { Others (septicaemia, malaria, cerebral } \\
\text { tumour, myocarditis) }\end{array}$ & $3(12.0)$ & $2(12.5)$ & 1 (11.11) \\
\hline Unknown & $1(4.0)$ & $0(0)$ & $1(11.11)$ \\
\hline
\end{tabular}

${ }^{*} \mathrm{X}^{2}=0.06 ; \mathrm{df}=1 ; \mathrm{P}>0.05 ; \dagger \mathrm{X}^{2}=0.02 ; \mathrm{df}=1 ; \mathrm{P}>0.05 ; \ddagger \mathrm{X}^{2}=1.71 ; \mathrm{df}=1 ; \mathrm{P}>0.05 ; \$ \mathrm{X}^{2}=0.97 ; \mathrm{df}=1 ; \mathrm{P}>0.05 ;$ $\| \mathrm{x}^{2}=1.40 ; \mathrm{df}=1 ; \mathrm{P}>0.05 ;$ sample may have more than one diagnosis; ${ }^{* *} \mathrm{x}^{2}=4.19 ; \mathrm{df}=1 ; \mathrm{P}<0.05$; $\dagger \dagger \mathrm{x}^{2}=1.89 ; \mathrm{df}=1 ; \mathrm{P}>0.05$

Table 2: Clinical profile of patients admitted to mental health centre, Dharwad

Physical comorbidity: One-third of psychiatric patients had comorbid physical illnesses like epilepsy, dysentery, tuberculosis, malaria, and severe anaemia, with significant female preponderance. Of which, $80 \%$ succumbed to death especially due to comorbid serious physical illnesses. Most common causes of death reported were congestive cardiac failure due to severe anaemia (11\%), aspiration pneumonia (6\%), tuberculosis (3\%), hypovolemic shock due to dysentery $(2 \%)$, and others (3\%; malaria, myocarditis, cerebral tumour, septicaemia).

Hospital stay and events: Mean total hospitalization of cases was $23.01 \pm 46.24$ months, with three-fourths of cases having stayed up to 24 months. Use of seclusions was documented in about $13 \%(n=11)$ cases, especially in males with aggressive behaviour. Two- 
thirds of sample attained complete remission within 24 months, while $27 \%$ ( $n=23)$ cases did not attain full remission even after 24 months of hospitalization. Family communication through letters was done in one-third cases for reasons of health, discharge and maintenance charges. $71 \%(n=60)$ cases were discharged and sent home with or without subsistence allowances, with mortality seen in $29 \%(\mathrm{n}=25)$ cases.

\section{Legal and administrative profile of psychiatric patients}

Ninety-four percent $(n=80)$ of the available ancient medical records were pertaining to the Indian Lunacy Act, 1912. Ninetythree percent of PwMI had non-criminal status and rest were prisoners $(7 \% ; n=6)$ at the time of admission. As per the then guiding Acts, the reception orders (Form-5) were duly sent in $93 \%(n=80)$ cases along with medical history sheet of behavioural observation (Form-D), medical certificate (Form-C or Form-3) certifying patients as insane, and physical fitness to travel issued by the government or practicing medical officers (Table-3).

\begin{tabular}{|c|c|c|c|}
\hline Characteristics & Total $=85(\%)$ & Male $=63(\%)$ & Female $=22(\%)$ \\
\hline \multicolumn{4}{|l|}{ Act related to mental health } \\
\hline Indian Lunacy Asylums Act, 1858 & $5(5.88)$ & $3(4.76)$ & $2(9.09)$ \\
\hline Indian Lunacy Act, 1912 & $80(94.12)$ & $60(95.24)$ & $20(90.91)$ \\
\hline \multicolumn{4}{|l|}{ Admission year } \\
\hline$\leq 1911$ & $5(5.88)$ & $3(4.76)$ & $2(9.09)$ \\
\hline $1912-1921$ & $29(34.12)$ & $24(38.09)$ & $5(22.73)$ \\
\hline $1922-1931$ & $43(50.59)$ & $30(47.62)$ & $13(59.09)$ \\
\hline $1932-1941$ & $8(9.41)$ & $6(9.52)$ & $2(9.09)$ \\
\hline \multicolumn{4}{|l|}{ Legal status } \\
\hline Non-criminal & $79(92.94)$ & $58(92.06)$ & $21(95.45)$ \\
\hline Criminal & $6(7.06)$ & $5(7.94)$ & $1(4.55)$ \\
\hline $\begin{array}{l}\text { Medical history sheet of behavioural } \\
\text { observation (Form } D ; N=81 \text { ) }\end{array}$ & $79(97.53)$ & $57(96.61)$ & $22(100)$ \\
\hline $\begin{array}{l}\text { Government Secretariat approval for } \\
\text { admission of criminal "lunatics" }(\mathrm{N}=6)\end{array}$ & $6(100)$ & $5(83.33)$ & $1(16.67)$ \\
\hline $\begin{array}{l}\text { Medical certificate of mental illness and } \\
\text { physical fitness to travel (Form } \mathrm{C} / 3 \text {; } \\
\qquad \mathrm{N}=81 \text { ) }\end{array}$ & $80(98.77)$ & $58(98.31)$ & $22(100)$ \\
\hline \multicolumn{4}{|l|}{ Type of admission } \\
\hline Reception Order (Form-5) & $81(95.29)$ & $59(93.65)$ & $22(100)$ \\
\hline Judicial Magistrate & $60(74.07)$ & $41(69.49)$ & $19(86.36)$ \\
\hline Commissioner of Police & $17(20.99)$ & $14(23.73)$ & $3(13.64)$ \\
\hline Prison authorities & $2(2.47)$ & $2(3.39)$ & $0(0)$ \\
\hline Military authorities & $2(2.47)$ & $2(3.39)$ & $0(0)$ \\
\hline Voluntary boarder & $4(4.71)$ & $4(6.35)$ & $0(0)$ \\
\hline \multicolumn{4}{|l|}{ Escort } \\
\hline Police personnel & $69(81.18)$ & $51(80.95)$ & $18(81.82)$ \\
\hline Hospital attenders & $9(10.59)$ & $5(7.94)$ & $4(18.18)$ \\
\hline Sepoys & $3(3.53)$ & $3(4.76)$ & $0(0)$ \\
\hline Relatives/self & $4(4.71)$ & $4(7.84)$ & $0(0)$ \\
\hline Days taken to escort (mean and S.D.) & $5.65 \pm 7.58$ & $6.29 \pm 8.39$ & $3.82 \pm 4.19$ \\
\hline \multicolumn{4}{|l|}{ Maintenance charges } \\
\hline Court exempted (non-resident pauper) & $59(69.42)$ & $40(63.49)$ & $19(86.36)$ \\
\hline Municipal (resident pauper) & $13(15.29)$ & $12(19.04)$ & $1(4.55)$ \\
\hline Self & $6(7.06)$ & $5(7.94)$ & $1(4.55)$ \\
\hline Relatives & $4(4.71)$ & $3(4.76)$ & $1(4.55)$ \\
\hline Military & $3(3.53)$ & $3(4.76)$ & $0(0)$ \\
\hline
\end{tabular}

Table 3: Legal profile of patients admitted to mental health centre, Dharwad

Ninety-five percent cases were admitted through the reception orders and only $4.7 \%$ cases got admitted as voluntary boarders. Reception orders were issued by the jurisdictional Judicial Magistrate (79.6\%; Figure-1), Commissioner of Police (20\%; Figure-2), Prison Superintendent (2.35\%), and military officer (2.35\%). Permission from the Government Secretariat at Bombay Castle was sought for prisoners with psychiatric disorders (7\%) before passing reception order by the jurisdictional Judicial Magistrate. 


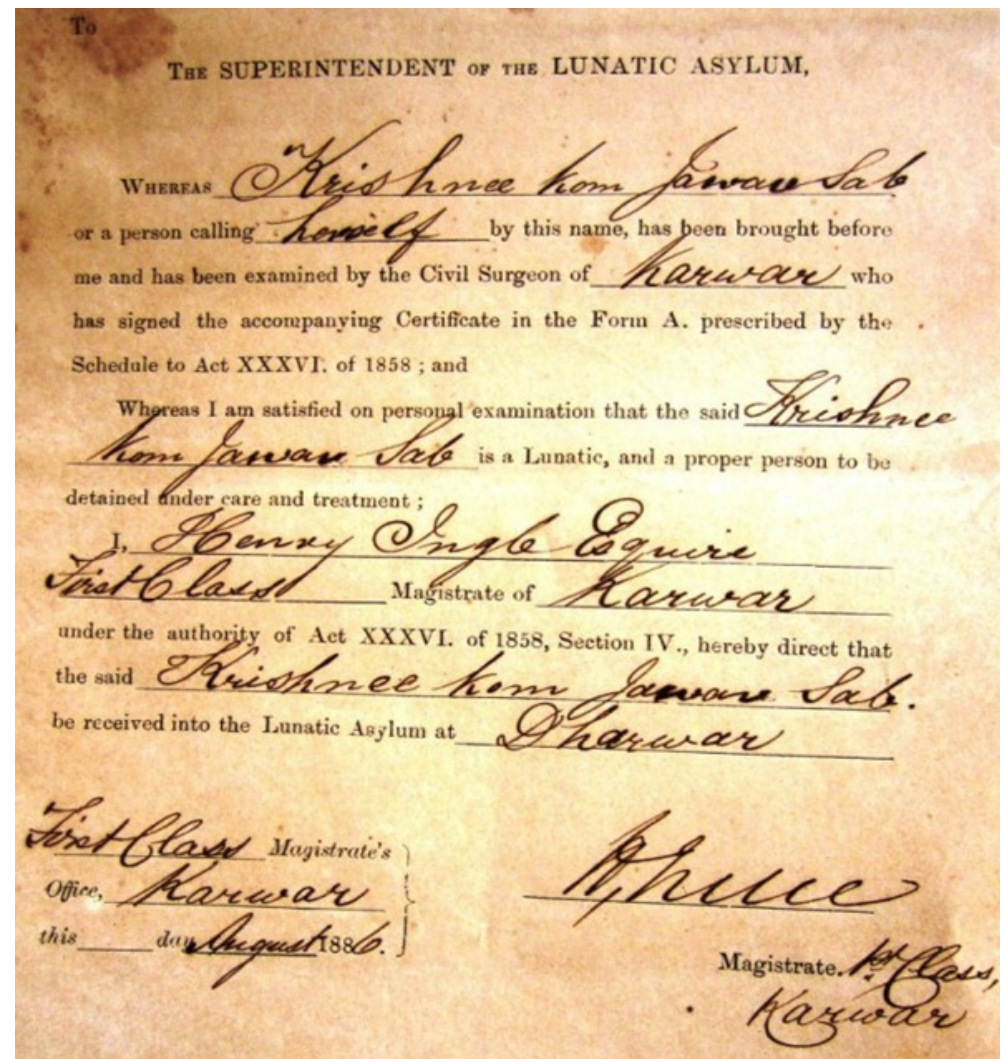

Figure 1: Reception order by the First Class Magistrate of Karwar dated August, 1886 under the Indian Lunatic Asylums Act, 1858

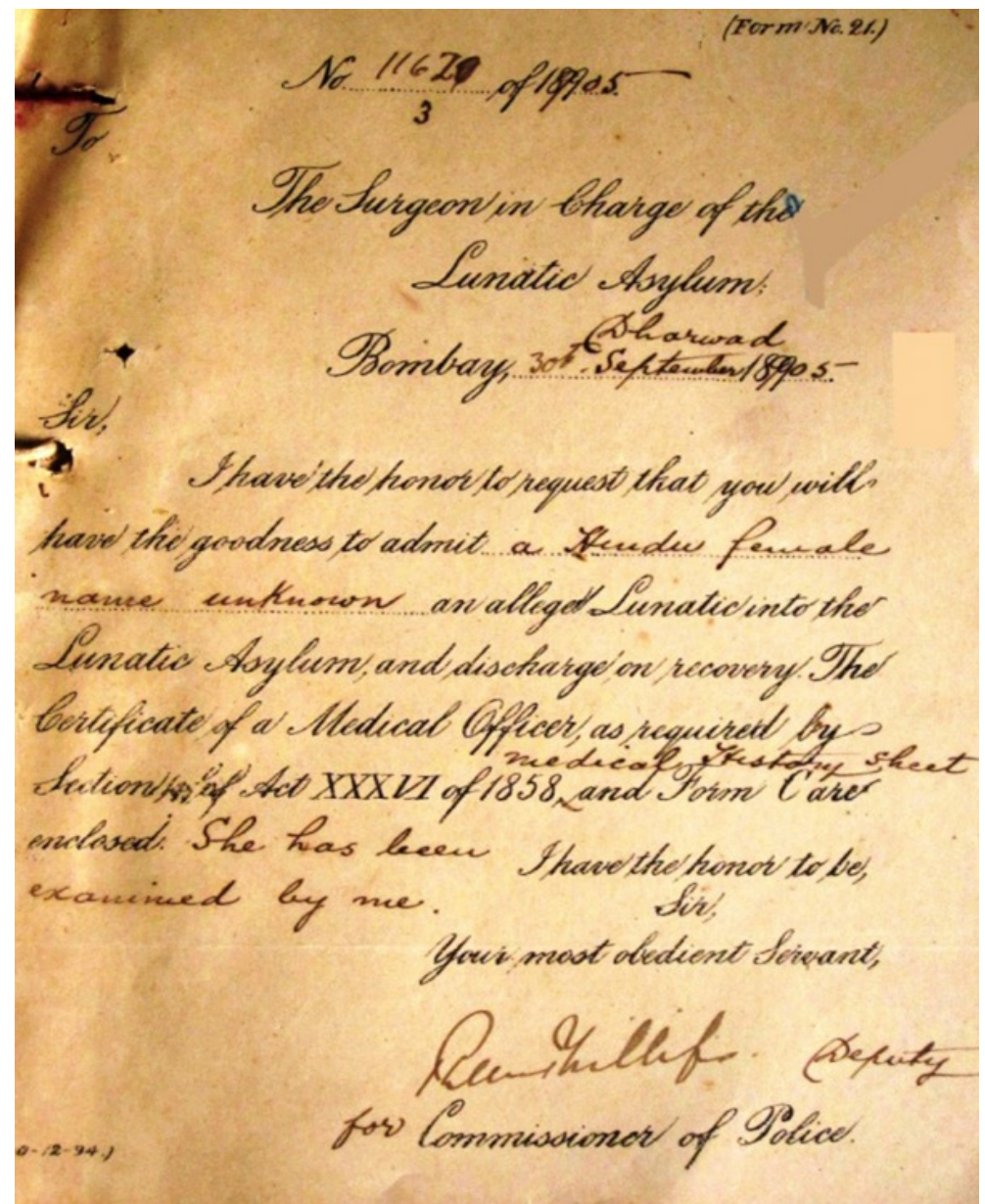

Figure 2: Reception order by the Commissioner of Police of Bombay dated 30th September, 1905 
Mean duration taken to escort from place of temporary detention to mental health centre was $5.65 \pm 7.58$ days, with majority escorted by police personnel $(81.9 \% ; n=69)$ either by roadways or railways. Nearly $70 \%(n=59)$ cases were exempted from payment of maintenance charges by court for being declared as 'pauper'. However, those PwMI who were 'pauper' and found to be residents of municipal limits were financially supported during hospitalisation by the jurisdictional municipal authorities ( $15 \%$; $\mathrm{n}=13$ ).

\section{Discussion}

The mean age of the sample being $32.53 \pm 9.65$ years may mean that more young and middle-aged adults, especially in the age range of 21-40 years were admitted to the Dharwad mental health centre. Distributions across gender, religion, education, economic and rural background possibly concurs with the socio-demographic profile of the country of that period, as census data was available only after independence.

Higher representation of lower socio-economic status with annual income of less than one thousand rupees, defined then as 'pauper', may represent the difficulty in paying the maintenance charges. Lower need for employment in majority of females reflects the work culture prevalent at those times when females were expected to be within houses as housewives and were unemployed, in contrast to current status of Indian women being considered in equal to males in most spheres of life. In general, these findings indicate that easy and affordable access to medical care was less available for middle and lower socio-economic groups and females in pre-Independence era.

Preponderance of single/separated/widow(er) status and one-third being destitutes is striking, possibly depicts lower level of social support rendered to the PwMI that reflects higher stigma levels prevalent in the society during those times compared to better levels of social support systems of current periods. Majority were living in a joint family setting which represents the typical agrarian standards of living in India during pre-independence era, in contrast to post-Industrial era with evolving and changing scenarios of current Indian society with inclination towards nuclear families.

Majority of the PwMI were admitted to mental health centre within 6 months of onset or exacerbation of mental illness, especially being admitted for first episodes (75\%) possibly denotes severity of first episodes in the sample necessitating detention in order to protect self, property, or society from detrimental behavior. This finding also supports the fact that more than one-third of cases exhibited dangerous/homicidal/suicidal behaviours, or were wandering naked and creating public nuisance, favouring detention through reception orders, in contrast to dramatic reduction of such cases following scientific advances in psychiatry and availability of better psychotropic medications.

Family history of psychiatric illnesses/suicide reported in 30\% of cases highlights possible underlying genetic influences in causation of mental illness. Postal communication remained the main and fruitful modem of informing family members/relatives regarding health status, discharge, death and payment of maintenance charges, that was positively reciprocated by letters, as many could not visit the mental health centre for reasons of accessibility due to poverty and also underdeveloped transport facilities from remote corners of Deccan India during pre-Independence era. Due to better accessibility, free medications provided by the Government and community mental health programmes, treatment compliance and adherence has improved since 1960s.

Majority of the PwMI (78\%) were hospitalised for psychiatric illness for up to 24 months, with males being detained for periods more than 24 months than females who were discharged within 24 months. This possibly indicates the nature and severity of mental illness in males who exhibit more aggressive behaviour compared to females. Aggressive behaviour was managed by medications with sedative and anti-convulsant properties like potassium bromide, magnesium sulphate, paraldehyde injections, chloral hydrate, sodium bicarbonate, and chloroform; with camphor-induced seizure therapy advised in difficult-to-treat patients with severe aggression. Seclusion in cells or use of physical restraints was necessitated in only $13 \%$ cases, especially males, which highlight the severity of aggression not amenable to sedative medications as also that majority cases were managed without seclusions during pre-independence era.

Ninety-eight percent of PwMI had one or more psychiatric diagnosis such as mania, insanity, and substance abuse/dependence (cannabis, alcohol, tobacco). Nearly half of the cases had mood disorders, one-third cases had psychotic disorders, one-fourth cases had substance use disorders, and one-tenth cases had epilepsy. Preponderance of cannabis- and tobacco-use disorders probably indicates its wide availability, accessibility and affordability during pre-independence era. Most common comorbidity in PwMI was physical morbidity (37\%), especially infectious illnesses (55\%), and psychiatric comorbidity, especially substance use disorders (21\%). Presence of acute and serious physical illnesses contributed to higher mortality in $80 \%$ cases. This suggests that effective medical management for cholera, tuberculosis, septicaemia, malaria, syphilis; and proper blood transfusions were less available at those times akin to psychiatric treatment.

Overcrowding at surrounding mental health centres at Thana and Poona under the Bombay Province led the Court to enquire about the availability of space at Dharwad mental health centre by telegraphs or postal communications to issue reception orders that usually accompanied medical history sheet, medical certificate of insanity and physical fitness to travel to the nearest mental health centre, in the prescribed forms as per the guiding Act of those times. Very few PwMI were voluntary boarders may indicate that many did not opt for voluntary admission, probably due to lack of awareness of concept of mental health and mental illness, or associated stigma of receiving care in asylum, or affordability issues such as maintenance charges of six annas per day. 
Pre-independence era witnessed provincial autonomy for health activities [6]. However, subsequent to the recommendations of the Bhore committee and also the emergence of psychotropic medications in India during late 1950s initiated efforts to integrate mental health care within Indian health system [7].

Although, personality acts in many ways; by predisposing to major psychiatric disorders such as depression or alcoholism, by leading to difficulties in relationship and social adjustment, by precipitating undesirable life events, and by impairing the ability to cope with a psychiatric or physical disorder, personality evaluation was not documented in the sample [8]. Probably, personality disorders were underdiagnosed or underreported as significant behavioural disorder during those times as the classification of personality types and related disorders was vague prior to 1950 s and major classificatory changes for personality disorders were available since DSM-III, 1980 [9].

\section{Conclusion}

Individuals admitted to Dharwad mental health centre during pre-Independence era were predominantly young adults, males, illiterates, from lower social economic status, single/separated/widow, had longer duration of illness and hospitalization, higher comorbid physical illnesses, higher mortality due to serious physical illnesses. Provisions of reception order for serving PwMI in order to protect self and society were more utilised compared to voluntary admissions or those with family members. Due to lack of adequate manpower and treatment centres, inaccessibility, non-affordability, lack of awareness, stigma, and non-availability of effective pharmacological and current scientific methods of treatment for PwMI during pre-Independence era, PwMI suffered from chronic ill health, disability, recurrent admissions, longer duration of hospitalisation, and higher mortality due to comorbid serious physical illnesses, all that could have reinforced stigma and fear towards PwMI, that has slowly changing over the past few decades with changing and evolving scientific treatment methods and community mental health programmes.

\section{Future Vision}

To develop institute into a centre of excellence for creating man power to meet mental health needs of the society. With huge catchment area and large population of end-users, there is enormous data for clinical health research. Multi-disciplinary research unit with state-of-the-art research laboratory is being established shortly. Institute on priority basis has already started recognised post-graduation degree courses in psychiatry (MD) and psychiatric nursing (DPN), and has taken steps to initiate super-speciality post-graduation courses in DM neurology, MCh neurosurgery, and post-graduation courses in MPhil clinical psychology, and MPhil in psychiatric social work. Phase-wise expansion of outpatient and inpatient neurology and neurosurgical services has been planned. Development of community mental health services is the top most priority of the institute, with training programmes for medical officers and health workers at various levels of community. Institute also serves regular prison mental health visits, school mental health programmes, community mental health programmes, including 'manochaitanya' to create mental health awareness in the society. In view of considerable number of patients getting admitted to forensic wards, specialized training courses in forensic psychiatry is being planned.

\section{References}

1. Turner J, Hayward R, Angel K, Fulford B, Hall J, et al. (2015) The history of mental health services in modern England: practitioner memories and the direction of future research. Med Hist 59: 599-624.

2. Parkar SR, Dawani VS, Apte JS (2001) History of psychiatry in India. J Postgrad Med 47: 73-6.

3. Foulkes RG (1961) British Columbia mental health services: historical perspective to 1961. Canad M A J 85: 649-55.

4. Vivekanand HR (1994) Karnataka institute of mental health. 27th Annual Conference of Indian Psychiatric Society, southern zonal branch, Dharwad (unpublished data)

5. Dharwad institute of mental health and neurosciences, Dharwad.

6. World Health Organization (1992) The ICD-10 classification of mental and behavioural disorders: clinical descriptions and diagnostic guidelines. 10th ed. Geneva: World Health Organization.

7. Van Ginneken N, Jain S, Patel V, Berridge V (2014) The development of mental health services within primary care in India: learning from oral history. Int J Ment Health Syst. 8: 30.

8. Kulkarni RR, Rao KN, Begum S (2013) Comorbidity of psychiatric and personality disorders in first suicide attempters: a case-control study. Asian J Psychiatry 6: 410-6.

9. American Psychiatric Association (1980) Diagnostic and statistical manual of mental disorders (DSM-III), 3rd ed. Washington DC: American Psychiatric Association. 


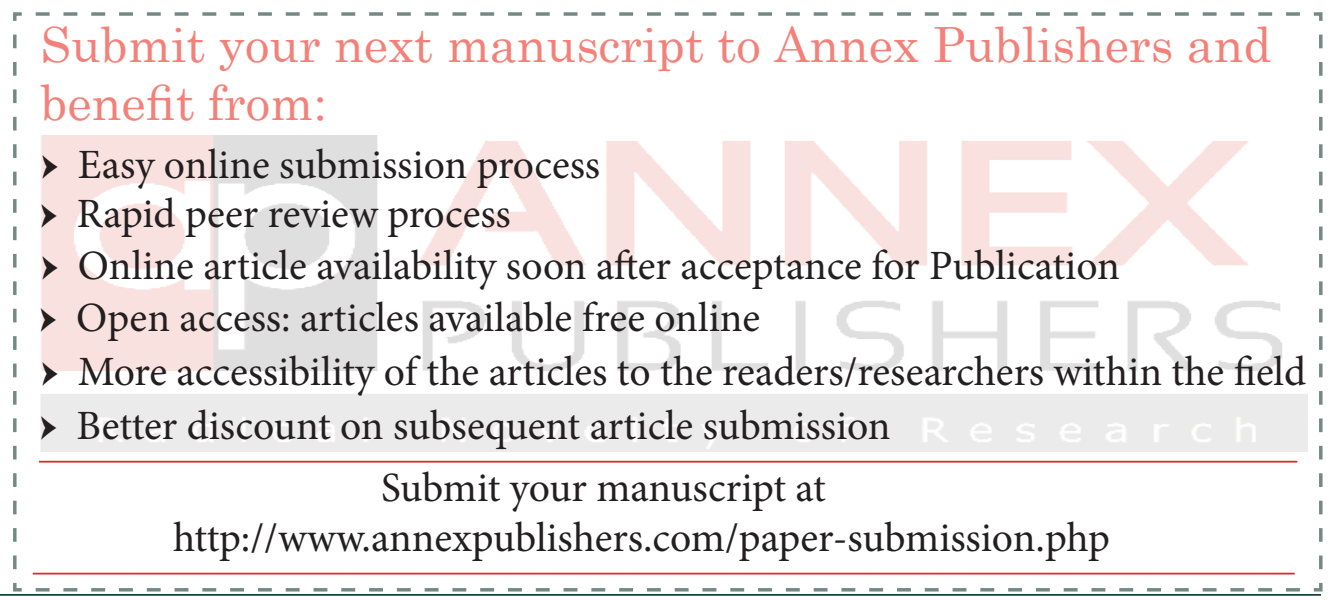

